\title{
El clima organizacional y su Influencia en el compromiso organizacional del personal administrativo en la Universidad Nacional José Faustino Sánchez Carrión, período 2016
}

The organizational climate and Its Influence on the organizational commitment of administrative staff at José Faustino Sánchez Carrion National University, 2016 period

Carlos Máximo Gonzales Añorga ${ }^{1}$

\section{RESUMEN}

Objetivo: Determinar de qué manera el clima organizacional influye en el compromiso organizacional del personal administrativo en la Universidad Nacional José Faustino Sánchez Carrión, período 2016. Métodos: El tipo de investigación fue aplicada a nivel correlacional, de diseño no experimental y de un corte transversal; porque el interés fundamental fue conocer si el clima organizacional influye en el compromiso organizacional del personal administrativo en la Universidad Nacional José Faustino Sánchez Carrión. El tamaño de la población fue de 535 servidores y se tomó como muestra aleatoria simple de 223 . La técnica utilizada para la recolección de datos fue la encuesta y como instrumento el cuestionario. Las técnicas estadísticas usadas para el análisis e interpretación de los daros la estadística descriptiva e inferencial y para el procesamiento se usó el Software SPSS Versión 23 y la hoja de cálculo Excel. Resultados: Hay una alta correlación entre las dos variables en estudio, donde clima organizacional está asociada estadísticamente al compromiso organizacional, según la asociación de variable con escala ordinal, por ser la significancia asintótica bilateral (Sig. $=0,00)$, estando por debajo de error máximo permisible $(a=0,005)$ inclusive $(a=0,01)$, relación muy significativa, entonces hay evidencia suficiente para rechazar la hipótesis nula (Ho: El clima organizacional y compromiso organizacional son Independientes ). Conclusiones: por tanto a un $95 \%$ de confianza se puede afirmar que, existe relación significativa entre el clima organizacional y el compromiso organizacional.

Palabras clave: Clima organizacional, compromiso organizacional, personal administrativo.

\section{ABSTRACT}

Objective: To determine how the organizational climate influences the organizational commitment of administrative staff at the Jose Faustino Sanchez Carrion National University, 2016. Methods: The type of research was applied at the correlational level, of non-experimental design and of a cross-section.; because the fundamental interest was to know if the organizational climate influences the organizational commitment of the administrative staff at the Jose Faustino Sanchez Carrion National University. The population size was 535 servers and it was taken as a simple random sample of 223. The technique used for data collection was the survey and as an instrument the questionnaire. The statistical techniques used for the analysis and interpretation of the descriptive and inferential statistics and for processing the SPSS Software Version 23 and the Excel spreadsheet were used. Results: There is a high correlation between the two variables under study, where the organizational climate is statistically associated with the organizational commitment, according to the association of variable with ordinal scale, as it is the bilateral asymptotic significance (Sig. $=$ $0,00)$, being below error maximum allowable $(a=0,005)$ inclusive $(a=0,01)$, very significant relationship, then there is sufficient evidence to reject the null hypothesis (Ho: The organizational climate and organizational commitment are independent). Conclusions: therefore, at $95 \%$ confidence, it can be affirmed that there is a significant relationship between the organizational climate and the organizational commitment.

Keywords: Organizational climate, organizational commitment, administrative staff 


\section{INTRODUCCIÓN}

Toda institución pública y privada, a través de un adecuado clima organizacional, busca satisfacer a sus trabajadores en relación a diversos elementos del proceso administrativo y de la administración del talento humano, y por ende en relación a la organización donde trabaja; por ello es importante el compromiso organizacional de un trabajador donde se identifica con su institución específicamente y con sus metas, donde anhela alcanzar siendo parte de ella y permanecer continuamente.

Louffat (2012), afirma que el clima organizacional es la tipificación del nivel de satisfacción del trabajador en vínculo a diferentes componentes del transcurso administrativo y de la administración del potencial humano y por ello en relación a la empresa donde laboran los mismos respecto a los demás integrantes que conforman la organización, a los procesos de trabajo y a las estructuras organizacionales.

El clima de la organización, se basa esencialmente por varias percepciones individuales de cada trabajador dentro de la organización, es muy frecuente que se pueda llegar a precisar como los patrones frecuentes de emociones, conducta y maneras, las cuales llegan a determinar la vida dentro de la organización y los lazos entre los grupos de trabajo, los empleados y el trabajo laboral, tal como lo afirma, Griffin y Moorhead (2010).

La investigación se justifica, porque teóricamente se fundamentó en conocer hechos que están provocando la falta de compromiso organizacional y de esta manera poder fortalecer el enfoque teórico; en lo practico se fundamenta a proporcionar los lineamientos para mejorar la situación de la institución universitaria, respecto a la falta de compromiso de su personal administrativo, hecho que estaría generando un clima organizacional poco apropiado.

Por lo tanto es pertinente abordar este tema por su importancia que significa que el personal administrativo conozca y maneje adecuadamente las normas, métodos y procedimientos que la institución implementa y desarrolla. También es imprescindible que la organización universitaria diseñe y estructure las tareas del personal administrativo, enfocándose en los objetivos de la institución. Esta actividad compete a los funcionarios, por tanto deberá realizar reuniones periódicas de inducción para motivar a sus colaboradores, y así mejorar su desempeño y compromiso con la institución.

La hipótesis planteada indica que el clima organizacional influye definitivamente en el compromiso organizacional del personal administrativo., de la Universidad Nacional José Faustino Sánchez Carrión.

Por lo expuesto anteriormente el objetivo general del presente trabajo fue determinar qué el clima organizacional influye en el compromiso organizacional del personal administrativo en la Universidad Nacional José Faustino Sánchez Carrión.

\section{MATERIAL Y MÉTODOS}

El diseño no experimental de acuerdo a Hernández, Fernández y Baptista (2014), se define como la investigación que se realiza sin manipular deliberadamente variables. Es decir, se trata de estudios donde no se hace variar en forma intencional las variables independientes para ver su efecto sobre otras variables. Lo que se hace en la investigación no experimental es observar fenómenos tal como se dan en su contexto natural, para posteriormente analizarlos.

Por los motivos expuestos, la presente investigación corresponde a una investigación de diseño no experimental, ya que busca observar los fenómenos referentes al clima organizacional y el compromiso organizacional en la Universidad Nacional José Faustino Sánchez Carrión.

Por su dimensión temporal, la investigación es de tipo transversal ya que los datos se recolectaron en un momento dado con la finalidad de estudiar las variables en un punto específico del tiempo. Corresponde a la investigación en un solo tiempo, descriptivo explicativo.

\section{RESULTADOS}

Tabla 1. Coeficientes de correlación y nivel de significancia del clima organizacional y su influencia sobre el compromiso organizacional.

\begin{tabular}{lcc}
\hline \multicolumn{1}{c}{ Variables } & \multicolumn{2}{c}{ Compromiso organizacional } \\
\hline & $\begin{array}{c}\text { Coeficiente de } \\
\text { correlación Rho } \\
\text { de Sperman }\end{array}$ & $\begin{array}{c}\text { Nivel de } \\
\text { Significación } \\
\text { (bilateral) }\end{array}$ \\
\hline $\begin{array}{l}\text { Estructura } \\
\text { organizacional }\end{array}$ & 0,412 & 0,000 \\
$\begin{array}{l}\text { Responsabilidad } \\
\text { Riesgo }\end{array}$ & 0,612 & 0,000 \\
Recompensas & 0,504 & 0,000 \\
Conflicto & 0,462 & 0,000 \\
$\begin{array}{l}\text { Clima } \\
\text { organizacional }\end{array}$ & 0,543 & 0,000 \\
\hline
\end{tabular}


Se procedió con la aplicación del estadístico de Spearman como se puede apreciar en la Tabla 1, se obtuvo un coeficiente de correlación moderada entre las dos variables y un $(p<0,005)$ efecto significativo (Rho $=0,412$ ). Por lo tanto, se confirma que la estructura organizacional influye en el compromiso organizacional del personal administrativo en la Universidad Nacional José Faustino Sánchez Carrión, período 2016.

Para la responsabilidad y su efecto sobre el compromiso organizacional se obtuvo un coeficiente de correlación moderada entre las dos variables y un efecto significativo $(p<0,05)$. Por lo tanto, se confirma que la responsabilidad influye en el compromiso organizacional del personal administrativo en la Universidad Nacional José Faustino Sánchez Carrión, período 2016.

Para la variable riesgo y su efecto sobre el clima organizacional se obtuvo un coeficiente de correlación moderada y un efecto significativo de $($ Rho $=0,504)$. Por lo tanto, se confirma que los riesgos influyen en el compromiso organizacional del personal administrativo en la Universidad Nacional José Faustino Sánchez Carrión, período 2016.

Para la variable recompensas y su efecto sobre el clima organizacional, se obtuvo un coeficiente de correlación moderada y un efecto significativo $(p<0,05)$. Por lo tanto, se confirma el clima organizacional influye en el compromiso organizacional del personal administrativo en la Universidad Nacional José Faustino Sánchez Carrión, período 2016.

Para la variable conflicto y su efecto sobre el compromiso organizacional, se obtuvo un coeficiente de correlación moderada y un efecto significativo $(p<0,05)$. por lo tanto se confirma que el conflicto influye en el compromiso organizacional del personal administrativo en la Universidad Nacional José Faustino Sánchez Carrión, período 2016influye en el compromiso organizacional.

Para la variable clima organizacional y su efecto sobre el compromiso organizacional, se obtuvo un coeficiente de correlación alta y un efecto significativo $(p<0,05)$. por lo tanto se confirma que el clima organizacional influye en el compromiso organizacional del personal administrativo en la Universidad Nacional José Faustino Sánchez Carrión, período 2016influye en el compromiso organizacional.

\section{DISCUSIÓN}

La investigación partió del análisis de la problemática que existe en el personal administrativo de la Universidad Nacional José Faustino Sánchez Carrión, donde empezamos esta parte final de la discusión, sustentado en los resultados obtenidos en la contrastación de la hipótesis general, el cual nos sirvió para demostrar que si existe influencia directa y significativa entre el clima organizacional y el compromiso organizacional con una "r" de Spearman igual a 0,810 y con un nivel de significancia del $99 \%$. Asimismo, en conjunto se observa que el clima organizacional, expresado en estructura organizacional, responsabilidad, riesgo, recompensa y conflicto influye en un $54,5 \%$ sobre el compromiso organizacional, con lo que se cumple con la hipótesis planteada en la investigación, al $95 \%$ de confianza.

Al respecto Ramírez y Domínguez (2012) en su tesis el clima organizacional y el compromiso institucional en las IES de Puerto Vallarta, concluye afirmando que el mejoramiento en el clima organizacional incidiría de manera positiva en un $58 \%$, corroborando en gran medida lo que nuestra hipótesis aseveró.

Respecto a la primera hipótesis específica: La estructura organizacional influye en el compromiso organizacional del personal administrativo en la Universidad Nacional José Faustino Sánchez Carrión, período 2016. Se demuestra de igual manera con la $r$ de Spearman igual a 0,412 que existe una relación media o moderada; esto es a causa que dentro de todos los aspectos conformados por la estructura organizacional la mayoría resalta que no están de acuerdo con las normas, métodos y procedimientos para realizar sus funciones, además de la estructuración de las tareas que cumple y tampoco con la jerarquía de responsabilidades que existe en la Universidad Nacional José Faustino Sánchez Carrión, lo que estaría causando que el personal se sienta parcialmente comprometido con la institución. Así al respecto Chiavenato (2014), sostiene que la estructura representa la percepción que tienen los miembros de la organización acerca de las obligaciones, de las reglas y de las políticas que se encuentran en una organización. Aseverando de esta manera que la estructura bajo la cual trabajan influyen en el compromiso organizacional.

Ahora bien, respecto a la segunda hipótesis: La responsabilidad influye en el compromiso organizacional del personal administrativo en la Universidad Nacional José Faustino Sánchez Carrión, período 2016. Al Igual que en la primera hipótesis específica, este se demuestra con la "r" de Spearman igual a 0,612 , la cual significa una relación media o moderada. Al respecto, Niño (2006) en su trabajo de investigación titulado "Incidencia del Clima Organizacional en el Desempeño Laboral del Personal Administrativo de la Vicepresidencia de Administración y Finanzas en la Empresa Tropicalum, C.A", concluye que tienen 
toda la libertad en la realización de sus labores, al igual que el compromiso de responsabilidad en sus obligaciones.

Respecto a la tercera hipótesis específica dice: Los riesgos influye en el compromiso organizacional del personal administrativo en la Universidad Nacional José Faustino Sánchez Carrión, período 2016. Con un "r" de Spearman igual a 0,504 la cual significa una correlación moderada. O sea el riesgo se relaciona significativamente con el compromiso organizacional. A mayor riesgo mayor compromiso organizacional óptimo. El mismo que Chiavenato (2014) menciona: El riesgo es la percepción del nivel de determinados objetivos y como se presentan en una situación de trabajo, que pueden ocurrir durante el desempeño de su labor. En la medida que la organización promueva la aceptación de riesgos calculados a fin de lograr los objetivos propuestos, estos ayudarán a mantener un compromiso profesional, necesario en toda organización.

Respecto a la cuarta hipótesis dice: Las recompensas influyen en el compromiso organizacional del personal administrativo en la Universidad Nacional José Faustino Sánchez Carrión, período 2016. Con una " $r$ " de Spearman igual a 0,462 , lo cual significa una correlación moderada. Contrastamos con Chiang, Salazar, Martín y Núñez (2011) en el artículo científico titulado "Clima organizacional y satisfacción laboral. Una comparación entre hospitales públicos de alta y baja complejidad". Dentro de la variable clima laboral, encontramos que la mala remuneración causa que el personal se desmotive totalmente, repercutiendo en su desempeño y desarrollando estrés, lo que puede ser el causante de la falta de compromiso de los trabajadores de la empresa.

Con el planteamiento de la quinta hipótesis menciona: El conflicto influye en el compromiso organizacional del personal administrativo en la Universidad Nacional José Faustino Sánchez Carrión, período 2016. Se demuestra al igual con una " $r$ " de Spearman a 0,462 una correlación moderada. Frente a ello, Chiavenato (2014) menciona que el conflicto es la confianza que un empleado pone en el clima de su organización o cómo puede asimilar sin riesgo las divergencias de opiniones. En este punto juega un rol muy importante una buena comunicación fluida entre las distintas escalas jerárquicas de la organización, lo que evitaría que se genere el conflicto.

\section{REFERENCIAS BIBLIOGRÁFICAS}

Chiang, M., Salazar, M., Martín, J., \& Núñez, A. (2011). Clima organizacional y satisfacción laboral. Una comparación entre hospitales públicos de alta y baja complejidad. Salud de los trabajadores, 19(1), 5-16.

Chiavenato, I. (2014). Introducción a la teoría general de la administración ( $8^{\mathrm{a}} \mathrm{Ed}$.). México D.F.: Mc Graw Hill interamericana.

Griffin, R. \& Moorheard, G. (2010). Comportamiento organizacional: Gestión de personas y organizaciones. EE. UU. Traducción México: Cengage Learning Editores, sa.

Hernández, R., Fernández, C. \& Baptista, P. (2014). Metodología de la Investigación (6 $6^{\text {ta }}$ Ed. México DF.: Mc Graw - Hill.

Louffat, E. (2012). Administración del potencial humano. $\left(2^{\circ} \mathrm{Ed}\right.$.). Cengage Learning.

Niño, L. (2006). Incidencia del Clima Organizacional en el Desempeño Laboral del Personal Administrativo de la Vicepresidencia de Administración y Finanzas en la Empresa Tropicalum, C.A. Aragua, Venezuela. Tesis de grado. Colegio Universitario de los Teques "Cecilio Acosta". Recuperado el 21 de Setiembre deo2013 de,

http://www.orestesenlared.com.ve/Tesis $\%$ 20WEb/133.pdf

Ramírez, A. \& Domínguez, L. (2012). El clima organizacional y el compromiso institucional en las IES de Puerto Vallarta. Investigación administrativa, 41(109), 2130.

\section{Correo electrónico:}

carlosmaximogonz@gmail.com

\section{Revisión de pares:}

Recibido: 16/02/2019

Aceptado: 17/12/2019 